\title{
Laboreal
}

Volume $6 \mathrm{~N}^{\circ} 2$ | 2010

Varia

\section{Para uma contextualização da prevenção em segurança e saúde ocupacional no sector da construção : contributos da formação de coordenadores de segurança e saúde}

Para una contextualización de la prevención en seguridad y salud ocupacionales en el sector de la construcción : contribuciones de la formación de coordinadores de seguridad y salud

Promotion de la contextualisation de la prévention en sécurité et santé au travail dans le bâtiment : contributions de la formation en coordination en sécurité et santé

Promoting work safety and health prevention contextualization in building sector: contributions of the safety and health coordinators' training

\section{Camilo Valverde}

\section{OpenEdition}

Journals

\section{Edição electrónica}

URL: http://journals.openedition.org/laboreal/8849

DOI: $10.4000 /$ laboreal. 8849

ISSN: 1646-5237

\section{Editora}

Universidade do Porto

\section{Refêrencia eletrónica}

Camilo Valverde, "Para uma contextualização da prevenção em segurança e saúde ocupacional no sector da construção : contributos da formação de coordenadores de segurança e saúde », Laboreal [Online], Volume $6 \mathrm{~N}^{0} 2$ | 2010, posto online no dia 01 dezembro 2010, consultado o 24 setembro 2020. URL : http://journals.openedition.org/laboreal/8849; DOI : https://doi.org/10.4000/laboreal. 8849

Este documento foi criado de forma automática no dia 24 setembro 2020.

Laboreal está licenciado com uma Licença Creative Commons - Atribuição-NãoComercial 4.0 Internacional. 


\section{Para uma contextualização da prevenção em segurança e saúde ocupacional no sector da construção : contributos da formação de coordenadores de segurança e saúde}

Para una contextualización de la prevención en seguridad y salud ocupacionales en el sector de la construcción : contribuciones de la formación de coordinadores de seguridad y salud

Promotion de la contextualisation de la prévention en sécurité et santé au travail dans le bâtiment : contributions de la formation en coordination en sécurité et santé

Promoting work safety and health prevention contextualization in building sector: contributions of the safety and health coordinators' training

Camilo Valverde

\section{REFERÊNCIA}

Valverde, C. (2010). Para uma contextualização da prevenção em segurança e saúde ocupacional no sector da construção : contributos da formação de coordenadores de segurança e saúde. Tese de Doutoramento, Faculdade de Psicologia e de Ciências de Educação da Universidade do Porto, Porto. 


\section{NOTA DO EDITOR}

Manuscrito recebido em : Novembro/2010

Aceite após peritagem em : Dezembro/2010

\section{Contexto e problemática}

1 Este trabalho foi realizado em Portugal no contexto do sector da construção civil e obras públicas. Trata-se de uma indústria marcada pela elevada sinistralidade (a taxa de frequência de acidentes e a percentagem de acidentes mortais apresentam valores acima da média quando comparados com outras indústrias e serviços [1]), por instabilidade organizativa (com recurso massivo a subcontratações) e laboral (com predomínio de relações de trabalho muito desregulamentadas e precárias), operando num contexto económico e social de grande competitividade e desemprego elevado, no qual ocorrem mudanças tecnológicas relevantes. Os modelos vigentes da gestão da prevenção em segurança e saúde no trabalho, baseados na tradicional prescrição de procedimentos de tipo regulamentar e técnico e no controlo e verificação de conformidades, têm manifestado dificuldades em enfrentar a variabilidade, a imprevisibilidade, a complexidade e as singularidades que caracterizam este sector.

2 Neste enquadramento, configura-se como uma alternativa adaptada o surgimento na indústria da construção da primeira directiva sectorial sobre higiene, segurança e saúde no trabalho : a Directiva Estaleiros (92/57/CEE) [2], sobre prescrições mínimas de segurança e saúde no trabalho a observar nos estaleiros temporários ou móveis, que prevê a criação de um actor específico - o coordenador de segurança e saúde na construção, que intervém em todas as etapas do processo de construção: desde a concepção até à demolição - com a finalidade de desenvolver a gestão da prevenção num sector económico em que as formas prevalecentes de regulação e de gestão da prevenção se mostram pouco eficazes.

3 No entanto, se as formas de conceber, implantar e regular as intervenções preventivas deste novo protagonista se alicerçarem, de forma tendencialmente reducionista, no recurso a abordagens de cariz técnico-regulamentar, estaremos perante uma decisão pouco consequente, sustentada numa lógica paradoxal: enfrentar problemas específicos através do recurso a concepções e instrumentos de análise e de actuação de carácter genérico, que acabam por se revelar manifestamente inadequados face à diversidade das situações que se verificam no terreno. É neste enquadramento que nos parece pertinente a proposta que consiste em preconizar a acção preventiva dos coordenadores de segurança e saúde a partir da análise e da transformação dos processos de trabalho, tendo em conta as suas condições concretas nas dinâmicas específicas dos estaleiros.

4 Neste enquadramento, elegemos como objecto de estudo a análise da formação destes novos actores para que possa constituir uma via possível para trans-formar as suas representações e abrir oportunidades para outras lógicas de gestão da prevenção. Particularmente, se essa formação estiver ancorada numa abordagem reflexiva das práticas e das concepções da prevenção, orientada para a construção de um colectivo profissional de preventores mais bem instrumentado para fazer face às descontinuidades que se têm vindo a impor nos sistemas produtivos, com potencial 
para gerar novos riscos profissionais, para os quais é necessário reequacionar formas diferentes de avaliação e de prevenção.

\section{Enquadramento científico-metodológico}

5 Adoptamos a abordagem teórico-metodológica denominada "paradigma de formação dos actores" inserida na tradição científica da psicologia do trabalho e da ergonomia da actividade, que confere um estatuto privilegiado à análise das actividades laborais enquanto dimensão estruturante dos processos de investigação e de intervenção que equacionam as relações entre a análise do trabalho, a gestão da prevenção em segurança e saúde no trabalho e a formação dos actores que actuam neste domínio (Lacomblez, 2001 ; Lacomblez \& Teiger, 2006 ; Teiger, 2002 ; Teiger \& Lacomblez, 2001 ; Teiger \& Lacomblez, 2005; Teiger \& Lacomblez, 2006). Trata-se de um projecto científico que assume como finalidade a adaptação do trabalho ao Homem e procura valorizar uma gestão alternativa da segurança e do bem-estar dos trabalhadores atenta ao desenvolvimento individual e colectivo. Para compreender e transformar as situações de trabalho, esta perspectiva estabelece a distinção entre o trabalho prescrito (a tarefa) e o trabalho real (a actividade). Questiona de forma frontal as diferenças de estatuto habitualmente atribuídas aos conhecimentos dos actores considerados como especialistas e como não especialistas, valorizando a partilha não hierarquizada das suas diferentes experiências. Sustenta que as concepções e as práticas da prevenção decorram e se estruturem sempre a partir do estudo multidisciplinar dos riscos no contexto laboral em que ocorrem, numa dinâmica participativa que mobilize os diversos actores envolvidos.

6 O trabalho de campo adoptou um plano metodológico de cariz qualitativo empreendido numa lógica de estudo de caso no terreno através da realização de dois estudos : a gestão da prevenção na construção da Ponte Infante D. Henrique na cidade do Porto e um programa de formação em coordenação de segurança e saúde na construção, realizado pela Ordem dos Engenheiros da Região Norte. 0 primeiro estudo, que ilustra algumas das especificidades do sector, envolveu o acompanhamento da execução da obra com recurso a dispositivos metodológicos de observações no terreno, de análise documental e de entrevistas com os actores da prevenção, com a finalidade de Identificar as opiniões que estes actores envolvidos na construção desta obra mobilizaram para caracterizar as concepções e as práticas subjacentes às intervenções que aí ocorreram no domínio da segurança e saúde. A análise de conteúdo das entrevistas com 14 actores da prevenção (agrupados nos seguintes grupos profissionais: 3 operadores, 3 chefias de base, 3 chefias de topo, 3 técnicos/ administrativos e 2 técnicos de segurança) foi realizada com recurso a um instrumento informático especializado denominado TROPES, que originou categorias que foram interpretadas com a ajuda de uma análise de componentes principais denominada CATPCA - Categorial Principal Component Analysis (Meulman \& Heiser, 2005). No segundo estudo, descrevemos os conteúdos e os processos de um programa formativo de coordenação de segurança e saúde promovido por uma entidade de referência neste domínio para, de acordo com o nosso referencial teórico, sugerirmos mudanças na formação destes profissionais. 


\section{Análise e discussão dos resultados}

7 O estudo de caso sobre o programa de prevenção implementado na construção da Ponte do Infante D. Henrique e a análise das representações dos actores da prevenção envolvidos na sua gestão, evidenciam uma grande diversidade nas formas de conceber e de realizar a gestão da prevenção. Efectivamente, os resultados mostram claramente que nos actores que protagonizaram a gestão da prevenção na construção da ponte estudada se verifica uma evidente distinção entre o mundo [3] (ver Béguin, 2005) da prevenção dos operadores e das chefias de proximidade e o mundo da prevenção dos técnicos da segurança e dos gestores de topo. Aparentemente, estamos perante dois mundos que não se encontram e que parecem traduzir formas muito diversas de conceber e, eventualmente, de realizar a prevenção dos riscos profissionais e a promoção do bem-estar dos trabalhadores envolvidos na gestão da segurança no estaleiro.

8 Esta constatação configura importantes consequências para a intervenção e, consequentemente, para a formação dos coordenadores de segurança e saúde que, tendo a missão de garantir a segurança e promover a saúde no sector da construção civil e obras públicas, têm de estar instrumentados para compreender estas situações e para promover acções reflexivas, de envolvimento, comunicação e partilha de experiências que facilitem formas de ver comuns : a construção de mundos partilhados (Béguin, 2005).

9 No estudo do programa de formação de coordenadores de segurança e saúde na construção, através da análise dos temas previstos, e pela observação participante resultante da frequência das sessões desenvolvidas, constata-se que os seus conteúdos estavam eminentemente focados em torno de questões de natureza legal e de natureza técnica. Foi dada particular evidência à legislação, à regulamentação e à prescrição de formas de actuar de cariz técnico e administrativo, operacionalizados em lógicas de tipo normativo, de controlo, de conformidade, de verificação e de prescrição. Também consideramos que as abordagens preventivas veiculadas tendiam a estar claramente alicerçadas em procedimentos e em normas de aplicação genéricas, consideradas como supostamente universais, sem equacionar as condições concretas em que se realizam as actividades laborais. Por norma, não era tida em conta a gestão da variabilidade, do aleatório, do imprevisto e do incerto, muito frequentes no quotidiano dos estaleiros da construção.

10 Emerge, assim, a pertinência de nos interrogarmos sobre a possibilidade deste tipo de formação, claramente tributária do paradigma que temos vindo a designar de técnicoregulamentar, poder contribuir para que a intervenção no estaleiro seja promotora de um mundo da prevenção que se traduz no seu acantonamento nos aspectos ligados à verificação da conformidade com normas e procedimentos prescritos.

\section{Conclusões e vias de reflexão possíveis}

11 Para promover a construção de mundos partilhados, o paradigma de formação dos actores preconiza a ancoragem da prevenção nas condições concretas de realização das actividade de trabalho no terreno, e propõe o intercâmbio/confronto não hierarquizado de saberes/experiências, sustentando a criação de comunidades 
científicas alargadas e a promoção de interfaces entre os actores. Esta abordagem formativa revela-se bem adaptada para equacionar a formação em coordenação da segurança e saúde e para contribuir para a contextualização da prevenção no sector da construção.

Consequentemente, poderíamos concluir que, formar os actores da prevenção requer que se eleja como unidade de análise, não o indivíduo, mas a rede de interfaces envolvida na obra. Esta rede de trocas resulta da conjugação/alinhamento de actores com pontos de vista diversos, com formas de ver e identidades diferentes, que são mobilizados para a realização da obra. Para esta execução ser mais efectiva, é necessário que os actores se articulem e que convirjam nos posicionamentos, nas lógicas e nos pontos de vista diferentes que, sem se absorverem/reduzirem uns aos outros, concorram para a concretização das actividades conjuntas requeridas pela obra, integrando sustentadamente a segurança e o bem-estar.

Esta proposta requer a criação de pontos de contacto nos estaleiros para conhecer e reconhecer os mundos diferentes, e para, subsequentemente, promover a construção de "mundos partilhados". Abrem-se, assim, possibilidades de novas sinergias entre os meios da prevenção e a psicologia do trabalho em torno do paradigma da formação dos actores, cujos eixos estruturantes são, justamente, a ancoragem nas situações de trabalho concretas e a valorização das trocas entre diferentes registos de conhecimentos (Teiger \& Lacomblez, 2001). Podemos, portanto, admitir que o paradigma da formação dos actores, proposto pela psicologia do trabalho e pela ergonomia da actividade, aparentemente, revela particular adequação para perspectivar a formação dos coordenadores de segurança e saúde, entendidos no seu papel preventivo de gestores de interfaces no sector.

De facto, a profissão/actividade dos coordenadores de segurança e saúde, e dos actores da prevenção, em geral, pode, com vantagem, reestruturar-se/reconstruir-se num processo de formação em análise ergonómica do trabalho. Este processo formativo tem potencial para induzir modulações diversas no posicionamento e nos conhecimentos dos preventores : permite-lhes alargar, aprofundar e, eventualmente, reconfigurar as relações a estabelecer entre formação, trabalho e prevenção. Nestes processos de desenvolvimento é possível que os actores da prevenção sejam confrontados com novas contradições do registo "injunção paradoxal" entre as "conformidades" com os regulamentos/procedimentos, que raramente são coerentes com os constrangimentos reais da actividade num contexto específico e, em certas situações, as conformidades serem passíveis de se configurar como entraves à prevenção. Esta situação ilustra a necessidade de terem de se equacionar as condições do contexto (sociais, organizacionais, gestionárias...) que são necessárias para garantir a sustentabilidade deste tipo de intervenções (Teiger \& Lacomblez, 2001).

[1] De acordo com dados de Alves Dias (2005) e da Inspecção Geral do Trabalho (IGT, 2004 e 2005).

[3] Béguin (2005) propõe a seguinte operacionalização para o conceito de mundo: "podemos definir o mundo como uma apropriação, pelo sujeito, de certas propriedades do real, no quadro da sua actividade histórica e socialmente situada" (p. 33, tradução livre). o mesmo autor considera que "um mundo consiste nos panos de fundo conceptuais, axiológicos e práxicos que formam sistema com os objectos da acção" (idem, p. 35, tradução livre). 


\section{BIBLIOGRAFIA}

Alves Dias, L. (2005). Segurança e saúde no trabalho da construção na União Europeia. Segurança, 168, Suplemento Especial, Novembro/Dezembro, 7-22.

Béguin, P. (2005). Concevoir pour les genèses professionnelles. In P. Rabardel \& P. Pastré (dir.), Modèles du sujet pour la conception (pp. 31-52). Toulouse : Octarès Éditions.

IGT (2004). Campanha europeia da construção 2003. [Em linha] Disponível em http:// www.igt.gov.pt/DownLoads/content/REL_FINAL_CAMP_EUR_CONST2003.pdf [Consultado em 11/06/2005].

IGT (2005). Coordenação da segurança e saúde do trabalho nos empreendimentos da construção. [Em linha] Disponível em http://www.igt.gov.pt/DownLoads/content/ Coordenacao_trabalho_empreendimentos_construcao.pdf [Consultado em 13/02/2006].

Lacomblez, M. (2001). Analyse du travail et élaboration des programmes de formation professionnelle. Relations Industrielles, 56, 3, 543-578.

Lacomblez, M., \& Teiger, C. (2006). Ergonomia, formações e transformações. In P. Falzon (Ed.), Ergonomia. (pp. 587-602). S. Paulo: Edgard Blücher.

Meulman, J., \& Heiser, W. (2005). SPSS Categories. Chicago: SPSS Inc.

Teiger, C. (2002). Origines et évolution de la formation à la prévention de risques “ gestes et postures » en France. Relations Industrielles, 57,3, 431-462.

Teiger, C., \& Lacomblez, M. (2001). Introduction des sessions du Séminaire “(Se) former pour transformer le travail », Paris : Conservatoire National des Arts et Métiers, Mai.

Teiger, C., \& Lacomblez, M. (2005). L'ergonomie et la trans-formation du travail et/ou des personnes : permanences et évolutions (1). Education Permanente, 165 (4), 9-28.

Teiger, C., \& Lacomblez, M. (2006). L'ergonomie et la trans-formation du travail et/ou des personnes : permanences et évolutions (2). Education Permanente, 166 (1), 9-28.

\section{NOTAS}

1. De acordo com dados de Alves Dias (2005) e da Inspecção Geral do Trabalho (IGT, 2004 e 2005).

2. A transposição da Directiva Estaleiros para o ordenamento jurídico do nosso país ocorreu através do Decreto-Lei 155/95, que foi posteriormente alvo de clarificação e revisão pelo DecretoLei 273/2003 de 29 de Outubro, actualmente em vigor

3. Béguin (2005) propõe a seguinte operacionalização para o conceito de mundo: "podemos definir o mundo como uma apropriação, pelo sujeito, de certas propriedades do real, no quadro da sua actividade histórica e socialmente situada" (p. 33, tradução livre). O mesmo autor considera que "um mundo consiste nos panos de fundo conceptuais, axiológicos e práxicos que formam sistema com os objectos da acção" (idem, p.35, tradução livre). 


\section{AUTOR}

\section{CAMILO VALVERDE}

Faculdade de Economia e Gestão da Universidade Católica Portuguesa, Rua Diogo Botelho, 1327, 4169-005 Porto. Centro de Psicologia da Universidade do Porto, Rua do Dr. Manuel Pereira da Silva, 4200-392 Porto

cvalverde@porto.ucp.pt 